\title{
Efeito de Solventes Orgânicos Usados como Veículos de Fungicidas no Controle In Vitro e In Vivo da Incidência e da Transmissão de Bipolaris sorokiniana em Sementes de Cevada*
}

\author{
Javier Toledo Barba ${ }^{1}$, Erlei M. Reis ${ }^{2} \&$ Carlos A. Forcelini' ${ }^{2}$ \\ ${ }^{1}$ Centro de Investigación Agrícola Tropical (CIAT), Santa Cruz, Bolívia; ${ }^{2}$ Faculdade de Agronomia e Medicina \\ Veterinária, Mestrado em Agronomia, Área de Concentração Fitopatologia, Universidade de Passo Fundo, \\ Cx. Postal 611, 99001-970, Passo Fundo, RS
}

(Aceito para publicação em 28/01/2003)

Autor para correspondência: Erlei Melo Reis

BARBA, J.T., REIS, E.M. \& FORCELINI, C.A. Efeito de solventes orgânicos usados como veículos de fungicidas no controle in vitro e in vivo da incidência e da transmissão de Bipolaris sorokiniana em sementes de cevada. Fitopatologia Brasileira 28:136-142. 2003.

\section{RESUMO}

O objetivo deste trabalho foi comparar e avaliar, in vitro e in vivo, o efeito de solventes orgânicos utilizados como veículos de fungicidas na erradicação do fungo em sementes de cevada. Foram empregados o monoetilenoglicol (MEG) e o propilenoglicol (PPG), ambos a $0,5,1$ e $2 \%$. Os fungicidas testados foram a iminoctadina, a iprodiona, o triadimenol, o triticonazol, o flutriafol e o difenoconazol. A incidência foi determinada pela ocorrência de B. sorokiniana em sementes plaquadas em meio seletivo. A erradicação foi obtida nos tratamentos com iminoctadina + MEG; iminoctadina + PPG (a 1 e $2 \%$ ) e iprodiona + PPG (2\%). A eficiência dos demais fungicidas foi melhorada com o emprego dos solventes orgânicos, mas sem alcançar a erradicação do fungo.
In vivo na testemunha foram registrados níveis de transmissão de $89,7 \%$ para o coleóptilo e de $12,3 \%$ para a plúmula. Diferentemente dos dados obtidos in vitro, o emprego do PPG influenciou muito pouco no controle da transmissão, pois os fungicidas comportaramse satisfatoriamente quando misturados com água. Os fungicidas iminoctadina e difenoconazol foram $100 \%$ efetivos em evitar a transmissão do fungo das sementes para os coleóptilos. Os solventes orgânicos mostraram potencialidade para melhorar a eficiência da maioria dos fungicidas testados in vitro, aspecto que não foi corroborado in vivo.

Palavras-chave adicionais: Hordeum vulgare, patologia de sementes, monoetilenoglicol, propilenoglicol

\section{ABSTRACT}

Effect of organic solvents used as vehicles for fungicides on the in vitro and in vivo control of incidence and transmission of Bipolaris sorokiniana in barley seeds

An important pathogenic feature of the fungus Bipolaris sorokiniana is its capacity to be transmitted through barley (Hordeum vulgare) seeds, sometimes in levels up to $100 \%$, which turns fungus eradication very difficult with the available fungicides. As an attempt to improve the control of the seed-borne fungus inoculum, two organic solvents (monoethyleneglycol - MEG and propyleneglycol - PPG, both at $0,5,1$, and $2 \%$ ) were tested as vehicle for fungicides (iminoctadine, iprodione, triadimenol, triticonazol, flutriafol, and difenoconazol) used for seed dressing. In vitro fungus eradication was obtained with iminoctadine + MEG, iminoctadine + PPG (at 1 and $2 \%$ ), and iprodione + PPG (2\%). The organic solvents also improved the other fungicides efficacy, but they did not reach a $100 \%$ control. The in vivo (growth chamber adjusted to $25 \pm 2{ }^{\circ} \mathrm{C}$ and $80-$ $95 \%$ RU) fungus transmission was $89,7 \%$ to coleoptiles and $12,3 \%$ to plumules. All fungicides reduced this process by more than $90 \%$ and the use of PPG did not improve fungicide performance significantly. Iminoctadine and difenoconazol completely inhibited the fungus transmission to coleoptiles. In conclusion, the positive in vitro effects of the organic solvents were not confirmed in vivo.

\section{INTRODUÇÃO}

A transmissão de patógenos por sementes é um mecanismo eficiente pelo qual os fitopatógenos são introduzidos em novas áreas de cultivo, disseminados a longas distâncias, selecionados e disseminados como raças específicas a determinados hospedeiros e distribuídos através da população de plantas como focos de inóculo primário (Baker \& Smith, 1966; Tanaka \& Machado, 1985).

\footnotetext{
*Parte da Dissertação de Mestrado do primeiro autor. Universidade de Passo Fundo (2001)
}

Cerca de 48 patógenos já foram relatados no mundo associados a sementes de cevada (Hordeum vulgare L.), incluindo não apenas fungos, mas também bactérias e vírus (Richardson, 1979). No Brasil, existe uma grande flutuação na prevalência dos patógenos nas sementes de cevada, de acordo com as regiões e as safras agrícolas. De modo geral, Cochliobolus sativus (Ito \& Kurib.) Drechs. \& Dastur [Bipolaris sorokiniana (Sacc.) Shoem.] e Pyrenophora teres (Died.) Drech. [Drechslera teres (Sacc.) Shoem.] são os organismos de maior ocorrência nos grãos de cevada (Diehl \& Minella, 1985).

Em geral, os danos produzidos por B. sorokiniana nas 
Efeito de solventes orgânicos usados como veículos de fungicidas...

sementes de cevada traduzem-se na diminuição da germinação, redução no rendimento e na qualidade dos grãos e do malte; além disso, o fato de ter a capacidade de infetar e ser transmitido pela semente torna o fungo de importância potencial para a cultura da cevada, sobretudo quando as condições ambientais se apresentam favoráveis ao desenvolvimento da doença.

No trigo (Triticum aestivum L.), estudos feitos sobre a eficiência de transmissão desse fungo relatam valores de até $88 \%$ ao coleóptilo (Reis \& Forcelini, 1993) e $38 \%$ à plúmula (Toledo et al., 1996). Em consequiência, devido à elevada eficiência da transmissão que $B$. sorokiniana apresenta, Reis (1987) considera que o controle desse fungo deve ser orientado à erradicação na semente, a fim de reduzir o inóculo primário na lavoura. Porém, a constatação de lotes de sementes de cevada altamente infettadas por este fungo, com incidências próximas a $100 \%$, tornam os fungicidas existentes no mercado incapazes de erradicar esses altos níveis de infeção e de impedir a passagem do fungo para a parte aérea da planta.

Um dos avanços no tratamento químico de sementes refere-se às possibilidades de se utilizar solventes orgânicos (Menten, 1996). Segundo Dhingra \& Muchovej (1980), o seu uso apresenta várias vantagens sobre os métodos convencionais, tais como: a) as sementes permanecem secas, não necessitando de nova secagem; b) não estimula o processo da germinação; c) evita a imbibição e o aumento de volume das sementes (inchaço) e, o mais importante, d) favorece a penetração de fungicidas na semente, o que evita a remoção por manipulação e a sua diluição em solos muito úmidos.

$\mathrm{O}$ tratamento de sementes com solventes orgânicos tem sido recomendado para sementes de oleaginosas e para sementes de hortaliças (Dhingra \& Muchovej, 1980).

O controle de fungos de sementes de cereais através do uso de fungicidas veiculados por solventes orgânicos tem sido pouco ou escassamente investigado no mundo. Vidhyasekaran (1980), em trabalhos de controle químico de Drechslera oryzae (Breda de Haan) Subram. \& Jain., em sementes de arroz (Oryza sativa L.), conseguiu erradicar o fungo de todas as partes da semente através da guazatina + diclorometano, quando essas foram imersas na mistura pelo tempo de uma hora. No Brasil, Purchio \& Muchovej (1990) relatam que as misturas de captam + benzeno e triadimenol + acetona podem reduzir significativamente a percentagem de $B$. sorokiniana em sementes de trigo, porém nenhuma das combinações testadas (fungicida + solvente) por esses autores logrou a erradicação do fungo-alvo de controle.

Nesse sentido, o presente trabalho objetivou avaliar in vitro e in vivo o efeito de solventes orgânicos utilizados como veículos de fungicidas na erradicação de $B$. sorokiniana em sementes de cevada.

\section{MATERIAL E MÉTODOS}

O presente trabalho foi conduzido nas dependências da Faculdade de Agronomia e Medicina Veterinária da Universidade de Passo Fundo - RS no período de junho/2000 a fevereiro/2001.

\section{Teste em laboratório in vitro}

Os fungicidas testados foram: iminoctadina $20 \%$ (70 g i.a./100 kg sementes), iprodiona 50\% (50 g i.a./100 kg), triadimenol 15\% (40 g i.a./100 kg), triticonazol 20\% (45 g i.a./100 kg), flutriafol 2,5\% (7,5 g i.a./100 kg) e difenoconazol 15\% (30 g i.a./100 kg). Os solventes orgânicos utilizados foram: monoetilenoglicol (MEG) e propilenoglicol (PPG), ambos nos volumes de 500, 1.000 e $2.000 \mathrm{ml} / 100 \mathrm{~kg}$ sementes $(0,5,1$ e $2 \%)$, comparados com água $(2000 \mathrm{ml} / 100 \mathrm{~kg}$ sementes) e uma testemunha (semente misturada com água). Foram utilizadas sementes da cultivar cevada BR 2, com incidência aproximada de B. sorokiniana de 58\%. Cada fungicida constituiu um ensaio com oito tratamentos.

Para cada tratamento, $100 \mathrm{~g}$ de sementes foram pesadas, acondicionadas em frascos de Erlenmeyer de 500 $\mathrm{ml}$ de volume, acrescidas do fungicida + solvente (previamente misturados num vortex por espaço de 30 a $60 \mathrm{~s}$ ) e agitadas durante $5 \mathrm{~min}$ até conseguir uma boa cobertura da semente. A seguir, foram distribuídas 400 sementes (unidade experimental constituída por dez placas de Petri com dez sementes cada uma e quatro repetições) em meio seletivo de Reis (Reis, 1983). As sementes foram incubadas em sala de crescimento sob fotoperíodo de $12 \mathrm{~h}$ a temperatura de $25 \pm 2{ }^{\circ} \mathrm{C}$, durante dez dias. Decorridos 11 dias do plaqueamento, as sementes foram examinadas sob microscópio estereoscópico, com magnitude de $40 \times$, para a observação da frutificação de $B$. sorokiniana. Considerou-se infetada a semente sobre a qual o fungo produziu, no mínimo, um conidióforo com um conídio.

O delineamento experimental foi de parcelas completamente casualizadas. Os valores obtidos (percentagem de incidência do fungo) foram submetidos à análise de variância (ANOVA) e as médias foram comparadas mediante o teste de Tukey $(\mathrm{P}>0.05)$. Previamente à análise de variância, os valores foram submetidos à análise de normalidade.

\section{Teste em câmara climatizada in vivo}

Efeito dos solventes orgânicos na germinação: Com a finalidade de detectar provável efeito fitotóxico dos solventes orgânicos na germinação e emergência das plântulas, executou-se um ensaio no qual foram comparados três tratamentos: semente + água, semente + MEG e semente + PPG. Cada solvente foi utilizado no volume de $2.000 \mathrm{ml}$ por $100 \mathrm{~kg}$ de sementes. A metodologia de tratamento das sementes foi idêntica ao do ensaio anterior. Em cada unidade experimental foram semeadas 50 sementes. $\mathrm{O}$ delineamento experimental foi de tratamentos completamente casualizados, com oito repetições. A avaliação do número de plântulas emergidas foi realizada aos 15 dias após da semeadura.

Os dados obtidos foram expressos em percentagem de plantas emersas e submetidos à análise de variância $(\mathrm{P}<0,05)$, comparando-se as médias pelo teste de Tukey (5\%). Previamente à análise de variância, os valores foram submetidos à análise de normalidade. 
Transmissão e controle: $O$ ensaio foi conduzido em função dos resultados obtidos no Experimento 1, no qual foram comparados 13 tratamentos, constituídos pelos seis fungicidas testados nas doses usadas in vitro, cada um deles misturado com água e com PPG, mais uma testemunha. Utilizaram-se sementes de cevada, da cultivar BR-2, naturalmente infetadas com B. sorokiniana (aproximadamente $41 \%$ ). O tratamento fungicida foi feito de forma idêntica àquela descrita no ensaio in vitro.

No ensaio in vivo, a unidade experimental foi constituída de uma moldura de madeira de $41 \times 28 \times 10 \mathrm{~cm}$ de altura, encaixada numa bandeja de alumínio de $46 \times 31 \times 5$ $\mathrm{cm}$ de altura, contendo areia + solo de horta $(3: 1)$, com $\mathrm{pH}$ corrigido para 6,0. A areia empregada possuía uma concentração de $6 \mathrm{ppm}$ de manganês. $\mathrm{O}$ substrato foi esterilizado em duas oportunidades, em autoclave a $121{ }^{\circ} \mathrm{C}$ e 1,5 atmosferas, por um período de $45 \mathrm{~min}$. $\mathrm{O}$ substrato foi irrigado 24 $\mathrm{h}$ antes da semeadura com água de torneira + adubo foliar (1 $\mathrm{ml} / \mathrm{l}$ de água). Em cada caixa foram semeadas 100 sementes a 2,5 $\mathrm{cm}$ de profundidade do solo.

As caixas foram mantidas sob condições de câmara climatizada, com temperatura $\left(25 \pm 2{ }^{\circ} \mathrm{C}\right)$ e luminosidade (fotoperíodo de $12 \mathrm{~h}$ ) controladas. A umidade relativa (80 $95 \%$ ) foi monitorada através de termohigrógrafo. A umidade do solo foi mantida mediante irrigação periódica para manutenção da capacidade de campo. A irrigação foi feita pela deposição da água no fundo da bandeja. Empregou-se o delineamento experimental de tratamentos completamente casualizados com quatro repetições.

$\mathrm{Na}$ avaliação da transmissão sintomática após a emergência das plântulas (três a quatro dias após a semeadura), os coleóptilos e plúmulas foram examinados a cada cinco dias, sendo marcados com um palito de dente aqueles que apresentaram lesões pardas em plúmulas, assim como as plântulas que morreram prematuramente. Em alguns casos, foram feitos isolamentos das plântulas mortas no aparecimento desses sintomas para se determinar o agente causal. Decorridos 35 dias após a semeadura, as extremidades apicais dos coleóptilos de cada uma das plântulas foram removidas e cortadas a 1$1,5 \mathrm{~cm}$ acima do nível do solo. Os segmentos cortados foram plaqueados imediatamente e sem desinfestação em meio de cultura seletivo (Reis, 1983). Os coléoptilos isolados foram classificados e separados em sintomáticos e assintomáticos. As placas contendo o meio e os coleóptilos foram mantidos por dez dias em sala de crescimento, com fotoperíodo de 12 h. Considerou-se infetado o coleóptilo sobre o qual ocorreu a esporulação do fungo, em exame sob microscópio estereoscópico $(50 \times)$. De igual modo, foram feitos isolamentos a partir das lesões em plúmulas pelo seu plaqueamento em meio seletivo para confirmar a presença do fungo-alvo deste estudo.

Os dados obtidos foram expressos em percentagem de coleóptilos infetados (sintomáticos + assintomáticos). A transmissão (\%) foi calculada de acordo com Goulart \& Paiva (1990). Com os dados gerados, calculou-se o controle com base na redução da transmissão $(\%)$ proporcionada pelos fungicidas em relação à testemunha não tratada.
Finalmente, os valores obtidos (in vitro e in vivo) foram submetidos à análise de variância $(\mathrm{P}<0,05)$, comparando-se as médias pelo teste de Scott \& Knott (5\%). Previamente à análise de variância, os dados foram transformados para arco seno $[\sqrt{ }(x+1) / 100]$. Outros dados obtidos aos 35 dias após da semeadura foram: plântulas emergidas (\%) e plântulas mortas (\%). Dessas avaliações, apenas a primeira foi analisada estatisticamente, sem necessidade de transformação.

\section{RESULTADOS E DISCUSSÃO}

Demonstrou-se o efeito significativo $(\mathrm{P}<0,05)$ do tratamento de sementes de cevada com as diferentes combinações fungicida + solvente na incidência e na eficiência no controle de B. sorokiniana (Tabelas 1 e 2). Em geral, a dose alta (2 1/100 kg sementes) dos solventes testados melhorou substancialmente a eficiência de controle da maioria dos fungicidas.

Os resultados mostraram haver um efeito mínimo ou quase nulo dos solventes orgânicos na melhora da eficiência de controle do fungicida iminoctadina, que, em mistura com água, evidenciou controle próximo a $100 \%$. Porém, quando o fungicida foi misturado com as doses superiores dos solventes testados (1 e 2 1), o fungo foi erradicado das sementes.

Com os demais fungicidas, o efeito dos solventes orgânicos foi variável, mas sempre com a tendência de melhorar sua eficiência, sobretudo quando foram usadas as doses mais altas do solvente. Em média, a dose de 11 proporcionou melhor eficiência do que quando misturados à água, 97 e 133\%, quando misturados com MEG e PPG; já a dose mais alta (2 1) melhorou ainda mais a eficiência dos mesmos, em 192 e $201 \%$, respectivamente.

Em relação ao desempenho dos fungicidas (excetuando a iminoctadina), é importante salientar que o único produto que erradicou $B$. sorokiniana das sementes de cevada foi iprodiona quando misturado com 21 de PPG; mesmo que junto ao flutriafol, foram os fungicidas que evidenciaram os menores incrementos na eficiência de controle ao serem misturados com os solventes orgânicos testados, pois, na mistura com água, já apresentavam controle superiores a $70 \%$. Controle superior a $90 \%$ foi obtido com os fungicidas flutriafol e difenoconazole quando misturados à dose alta de PPG, principalmente. Um outro aspecto que deve ser salientado, é o fato de a combinação fungicida + água, nos produtos triadimenol, triticonazol e difenoconazol, ter determinado níveis de controle mais baixos $(<21 \%)$. Por outro lado, a eficiência foi melhorada substancialmente com o uso da dose alta dos solventes (média: 298\% para MEG e 312\% para PPG), sendo que a melhor resposta foi obtida com o difenoconazol, com incrementos de 372 (+ MEG) e 417\% (+ PPG).

$\mathrm{O}$ efeito do tratamento de sementes com fungicida + água e fungicida + PPG (Tabela 3) demonstrou que os tratamentos testados mostraram diferença significativa $(\mathrm{P}<$ $0,05)$ entre si. Dentre a combinação fungicida + água, destacou-se o fungicida iminoctadina, sendo o único que 
Efeito de solventes orgânicos usados como veículos de fungicidas...

TABELA 1 - Incidência (in vitro) de Bipolaris sorokiniana em sementes de cevada (Hordeum vulgare) tratadas com fungicidas + solventes orgânicos

\begin{tabular}{|c|c|c|c|c|c|c|c|}
\hline \multirow{3}{*}{$\begin{array}{l}\text { Solvente } \\
\text { ou veículo }\end{array}$} & \multirow{3}{*}{ Dose ${ }^{1}$} & \multicolumn{6}{|c|}{ Fungicidas ${ }^{2}$} \\
\hline & & $1^{3}$ & 2 & 3 & 4 & 5 & 6 \\
\hline & & & & INCIDÊI & $(\%)$ & & \\
\hline Água & 2,0 & 0,3 & $14,5 \mathrm{bc}$ & $50,5 \mathrm{ab}$ & $50,5 \mathrm{bc}$ & $16,5 \mathrm{bc}$ & $38,5 \mathrm{~b}$ \\
\hline MEG $^{5}$ & 0,5 & 0,3 & $18,5 b^{4}$ & $48,8 \mathrm{ab}$ & $54,0 \mathrm{ab}$ & $16,5 \mathrm{bc}$ & $29,8 \mathrm{c}$ \\
\hline MEG & 1,0 & 0,0 & $4,3 \mathrm{~d}$ & $36,8 \mathrm{bcd}$ & $39,8 \mathrm{~cd}$ & $11,3 \mathrm{c}$ & $19,0 \mathrm{~d}$ \\
\hline MEG & 2,0 & 0,0 & $0,3 \mathrm{~d}$ & $21,0 \mathrm{~d}$ & $20,3 \mathrm{e}$ & $3,8 \mathrm{~d}$ & $6,8 \mathrm{ef}$ \\
\hline $\mathrm{PPG}^{5}$ & 0,5 & 0,3 & $11,3 \mathrm{c}$ & $47,3 \mathrm{abc}$ & $52,0 \mathrm{abc}$ & $19,8 \mathrm{~b}$ & $36,5 \mathrm{bc}$ \\
\hline PPG & 1,0 & 0,0 & $4,3 \mathrm{~d}$ & $32,0 \mathrm{~cd}$ & $30,3 \mathrm{de}$ & $12,3 \mathrm{c}$ & $13,8 \mathrm{de}$ \\
\hline PPG & 2,0 & 0,0 & $0,0 \mathrm{~d}$ & $21,3 \mathrm{~d}$ & $20,5 \mathrm{e}$ & $3,0 \mathrm{~d}$ & $2,5 \mathrm{f}$ \\
\hline Testemunha & ---- & 57,3 & $53,0 \mathrm{a}$ & $60,5 \mathrm{a}$ & $63,8 \mathrm{a}$ & $61,3 \mathrm{a}$ & $47,0 \mathrm{a}$ \\
\hline $\mathrm{CV}(\%)$ & & & 18,03 & 17,80 & 13,12 & 15,26 & 13,25 \\
\hline FC & & & $212,2 * *$ & $16,9 * *$ & $36,2 * *$ & $179,9 * *$ & $100,8^{* *}$ \\
\hline
\end{tabular}

(1) $1 / 100 \mathrm{~kg}$ de sementes.

(2) 1. iminoctadina; 2. iprodiona; 3. triadimenol; 4. triticonazole; 5. flutriafol; 6. difenoconazole.

(3) Cada fungicida representa um ensaio com oito tratamentos, médias comparadas na vertical.

(4) Médias seguidas pela mesma letra, na vertical, não diferem estatisticamente entre si pelo teste de Tukey (5\%).

(5) $\mathrm{MEG}=$ monoetilenoglicol; $\mathrm{PPG}=$ propilenoglicol.

Nota: O ensaio do fungicida iminoctadina não foi analisado estatisticamente por não apresentar distribuição normal.

TABELA 2 - Controle de Bipolaris sorokiniana (in vitro) pelo tratamento de sementes de cevada (Hordeum vulgare) com fungicida + solventes orgânico

\begin{tabular}{|c|c|c|c|c|c|c|c|}
\hline \multirow{3}{*}{$\begin{array}{l}\text { Solvente } \\
\text { ou veículo }\end{array}$} & \multirow{3}{*}{ Dose $^{1}$} & \multicolumn{6}{|c|}{ Fungicidas ${ }^{2}$} \\
\hline & & $\mathbf{1}^{3}$ & 2 & 3 & 4 & 5 & 6 \\
\hline & & \multicolumn{5}{|c|}{ CONTROLE (\%) } & \\
\hline Água & 2,0 & 99,5 & 72,6 & 16,5 & 20,9 & 73,1 & 18,1 \\
\hline $\mathrm{MEG}^{4}$ & 0,5 & 99,5 & 66,1 & 19,3 & 15,4 & 73,1 & 36,6 \\
\hline MEG & 1,0 & 100,0 & 91,9 & 39,2 & 37,6 & 81,6 & 59,6 \\
\hline MEG & 2,0 & 100,0 & 99,4 & 65,3 & 68,2 & 93,8 & 85,5 \\
\hline $\mathrm{PPG}^{4}$ & 0,5 & 99,5 & 78,7 & 21,8 & 18,5 & 67,7 & 22,3 \\
\hline PPG & 1,0 & 100,0 & 91,9 & 47,1 & 52,5 & 79,9 & 70,6 \\
\hline PPG & 2,0 & 100,0 & 100,0 & 64,8 & 67,9 & 95,1 & 93,6 \\
\hline
\end{tabular}

(1) $1 / 100 \mathrm{~kg}$ de sementes.

(2) 1. iminoctadina; 2. iprodiona; 3 . triadimenol; 4. triticonazole; 5 . flutriafol; 6. difenoconazole.

(3) Cada fungicida representa um ensaio com oito tratamentos, médias comparadas na vertical.

(4) $\mathrm{MEG}=$ monoetilenoglicol; $\mathrm{PPG}=$ propilenoglicol.

erradicou B. sorokiniana das sementes. Os fungicidas iprodiona e flutriafol ocuparam um segundo grupo, com controles de 83,5 e $87,0 \%$, respectivamente, ao passo que o triadimenol, o triticonazol e o difenoconazol evidenciaram o mais baixo nível de controle $(<50 \%)$. Dentro das combinações fungicida + PPG, todas se mostraram estatisticamente similares, sendo que iminoctadina, iprodiona e flutriafol foram as que conseguiram erradicar o fungo da semente. $\mathrm{O}$ restante dos tratamentos apresentou controle superior a $95 \%$. Em média, o uso do PPG melhorou significativamente a eficiência dos fungicidas testados, em $84,2 \%$, sem considerar a iminoctadina. Esses níveis de controle são confirmados pelos dados obtidos no primeiro ensaio, no qual os fungicidas triadimenol (126\%), triticonazol (100\%) e, principalmente, difenoconazol (160\%) foram os mais favorecidos pela mistura com o solvente.

A análise de variância evidenciou não existir diferença significativa $(P<0,05)$ entre os tratamentos testados. No tratamento 1 (semente + água), obteve-se o valor mais alto, com $87,8 \%$; seguido pelo tratamento 3 (semente + PPG), com $83,3 \%$, e ocupando o último lugar o tratamento 2 (semente + MEG), com 81,3\%.

Para os dados de percentagem de emergência, infecção, transmissão e eficiência de controle (Tabela 3) registraramse diferenças estatisticamente significativas $(P<0,05)$ entre os tratamentos testados.

Em relação à emergência de plântulas, quase todos os tratamentos mostraram um comportamento similar, sendo o tratamento 10 (triadimenol + PPG) o único estatisticamente inferior aos restantes. 


\section{J.T. Barba et al.}

TABELA 3 - Controle in vitro e in vivo da incidência e da transmissão de Bipolaris sorokiniana mediante o tratamento de sementes de cevada (Hordeum vulgare) com fungicida + solvernte orgânico (PPG)

\begin{tabular}{|c|c|c|c|c|c|c|}
\hline \multirow[b]{2}{*}{ Tratamento } & \multicolumn{2}{|c|}{ In vitro } & \multicolumn{4}{|c|}{ In vivo } \\
\hline & $\begin{array}{c}\text { Incidência } \\
(\%)\end{array}$ & $\begin{array}{c}\text { Controle } \\
(\%)\end{array}$ & $\begin{array}{c}\text { Emergência } \\
(\%)\end{array}$ & $\begin{array}{c}\text { Coleóptilos } \\
\text { infetados }(\%)\end{array}$ & $\begin{array}{c}\text { Transmissão } \\
(\%)^{1}\end{array}$ & $\begin{array}{c}\text { Controle } \\
\text { transmissão }(\%)\end{array}$ \\
\hline Testemunha & $40,7 \mathrm{a}$ & 0,0 & $89,0 \mathrm{a}$ & $36,5 \mathrm{a}$ & 89,68 a & 0,0 \\
\hline Iminoctadina + água & $0,0 \mathrm{~d}^{2}$ & 100,0 & $88,0 \mathrm{a}$ & $0,0 \mathrm{~d}$ & $0,00 \mathrm{~d}$ & 100,0 \\
\hline Iprodinona + água & $6,7 \mathrm{c}$ & 83,5 & 88,0 a & $0,5 \mathrm{~d}$ & $1,23 \mathrm{~d}$ & 98,6 \\
\hline Triadimenol + água & $23,3 \mathrm{~b}$ & 42,8 & 86,0 a & $11,5 \mathrm{~b}$ & $28,26 \mathrm{~b}$ & 68,5 \\
\hline Triticonazo e + água & $20,7 \mathrm{~b}$ & 49,1 & $88,0 \mathrm{a}$ & $2,5 \mathrm{c}$ & $6,14 \mathrm{c}$ & 93,2 \\
\hline Flutriafol + água & $5,3 \mathrm{c}$ & 87,0 & 86,0 a & $2,0 \mathrm{c}$ & $4,91 \mathrm{c}$ & 94,5 \\
\hline Difeno conazol + água & $25,3 \mathrm{~b}$ & 37,8 & $93,5 \mathrm{a}$ & $0,0 \mathrm{~d}$ & $0,00 \mathrm{~d}$ & 100,0 \\
\hline Iminoctadina + PPG & $0,0 \mathrm{~d}$ & 100,0 & $83,0 \mathrm{a}$ & $0,0 \mathrm{~d}$ & $0,00 \mathrm{~d}$ & 100,0 \\
\hline Irodiona + PPG & $0,0 \mathrm{~d}$ & 100,0 & $87,0 \mathrm{a}$ & $0,5 \mathrm{~d}$ & $1,23 \mathrm{~d}$ & 98,6 \\
\hline Triadimenol + PPG & $1,3 \mathrm{~d}$ & 96,8 & $72,0 \mathrm{~b}$ & $2,0 \mathrm{c}$ & $4,91 \mathrm{c}$ & 94,5 \\
\hline Triticonazol + PPG & $0,7 \mathrm{~d}$ & 98,3 & $84,5 \mathrm{a}$ & $0,5 \mathrm{~d}$ & $1,23 \mathrm{~d}$ & 98,6 \\
\hline Flutriafol + PPG & $0,0 \mathrm{~d}$ & 100,0 & $87,0 \mathrm{a}$ & $1,5 \mathrm{c}$ & $3,69 \mathrm{c}$ & 95,9 \\
\hline Difenoconazol + PPG & $0,7 \mathrm{~d}$ & 98,3 & $89,5 \mathrm{a}$ & $0,0 \mathrm{~d}$ & $0,00 \mathrm{~d}$ & 100,0 \\
\hline FC & $103,08 * *$ & -- & $5,03 * *$ & $59,00 * *$ & $58,37 * *$ & -- \\
\hline $\mathrm{CV}(\%)$ & 13,19 & -- & 5,14 & 21,91 & 31,42 & -- \\
\hline
\end{tabular}

(1) Dados transformados para arco seno [v( $\mathrm{x}+1) / 100]$

(2) Médias seguidas pela mesma letra não diferem estatisticamente entre si pelo teste de Scott \& Knott a 5\% de probabilidade

Trinta e cinco dias após a semeadura, os tratamentos mostraram comportamento variável, registrando-se na testemunha uma taxa de transmissão próxima a $90 \%$. Dentre as combinações, o tratamento 3 (triadimenol + água) situou-se num segundo grupo, depois da testemunha, com $28,3 \%$ de transmissão, situação que foi reduzida até $4,91 \%$ com o emprego do PPG. Num terceiro grupo, situaram-se os tratamentos 4 (triticonazol + água) e 5 (flutriafol + água), sendo que só o flutriafol não sofreu nenhuma melhora quando misturado ao PPG. Por último, os tratamentos 1 (iminoctadina. + água), 2 (iprodiona + água), 6 (difenoconazol + água), 8 (iminoctadina. + PPG), 9 (iprodiona + PPG), 11 (triticonazol + PPG) e 13 (difenoconazol + PPG) evidenciaram o melhor comportamento (estatisticamente semelhantes), com transmissão que oscilou entre zero e 1,23\%. Entre eles, os fungicidas iminoctadina e difenoconazol, em combinação com água ou com PPG, foram os que impediram totalmente a transmissão do fungo aos coleóptilos (100\% de controle). Em geral, os resultados obtidos in vivo mostram que o emprego do PPG melhorou pouco a eficiência de controle dos fungicidas (média de $9 \%$, sem levar em conta a iminoctadina), pois, por si só, em mistura com água, foram capazes de reduzir a eficiência da passagem do fungo para os órgãos aéreos. Porém, é evidente que o fungicida triadimenol foi o mais favorecido, com $38 \%$ de aumento na sua eficiência; ao contrário, sua mistura com PPG reduziu significativamente a germinação das sementes.

A metodologia permitiu quantificar o potencial de transmissão de $B$. sorokiniana das sementes às plúmulas e folhas primárias, sendo a eficiência da transmissão, na testemunha, de até $20 \%$ (média: $12 \%$ ). O único tratamento com fungicida no qual ainda houve a transmissão do fungo a esses órgãos foi o triadimenol com 3,7 (+ água) e 2,5\% (+ PPG).

Segundo Reis \& Forcelini (1993), a presença dos patógenos necrotróficos na semente de cereais de inverno tem assegurado uma convivência indefinida daqueles com o hospedeiro, o que ocorre porque a maioria dos métodos de controle recomendados não é eficiente na sua erradicação. Por isso, existe a necessidade de se selecionar ou desenvolver métodos eficientes na erradicação desses patógenos, tarefa que não é fácil, segundo os autores. Os resultados obtidos nos testes de laboratório (in vitro) confirmam essa afirmação, pois, apesar de se ter melhorado a eficiência da maioria dos fungicidas testados mediante o emprego de solventes orgânicos, em substituição à água, a erradicação de $B$. sorokiniana das sementes de cevada só foi possível com os fungicidas iminoctadina e iprodiona. Estudos realizados por Vidhyasekaran (1980), nos quais se objetivou melhorar a eficiência dos fungicidas na erradicação de $D$. oryzae em sementes de arroz, demonstraram que o único fungicida que conseguiu atingir esse objetivo foi a guazatina, em combinação com o diclorometano, e quando as sementes foram imersas na solução por 1 h. Por outro lado, Purchio \& Muchovej (1990) reportaram que a eficiência de alguns fungicidas no controle de $B$. sorokiniana em sementes de trigo foi incrementada com o emprego de solventes orgânicos.

Nenhum dos solventes orgânicos empregados (dose: 2 1/100 kg sementes) afetou significativamente a germinação e a emergência das plântulas. Estudos desenvolvidos por Purchio \& Muchovej (1990) concluíram, de igual modo, que os solventes benzeno, diclorometano e tetracloreto de carbono não exerceram nenhum efeito negativo sobre a germinação das sementes de trigo, ao passo que, quando foram imersas em acetona ou etanol, os efeitos detrimentais na germinação foram evidentes, sobretudo quando foi empregado o etanol. Por outro lado, Braccini et al. (1996), em estudos objetivando avaliar o efeito do estresse hídrico induzido por soluções de 
Efeito de solventes orgânicos usados como veículos de fungicidas...

cloreto de sódio, manitol e polietilenoglicol sobre a germinação e vigor de sementes de soja [Glycine max (L.) Merril], determinaram que as características avaliadas podem ser severamente afetadas à medida que a concentração das soluções osmóticas aumenta, sendo mais adversas com o polietilenoglicol. Em vista dessa conclusão, é importante salientar que, em estudos preliminares, mas sem repetições, foi possível observar reduções de até $50 \%$ na emergência de plântulas de cevada quando a semente foi misturada com MEG a $2 \%$ e armazenada por mais de dez dias antes da semeadura. Essa situação não se evidenciou com o PPG, razão pela qual este foi escolhido para realizar o ensaio de transmissão e de controle. Além disso, em observações realizadas nos ensaios de laboratório (in vitro), o efeito sobre a germinação das sementes foi também constatado, principalmente quando armazenadas por cinco a 14 dias. Os resultados obtidos no presente ensaio não refletem o exposto anteriormente talvez porque a semente empregada tenha sido semeada 24 a $30 \mathrm{~h}$ após o tratamento com o MEG.

Os resultados de transmissão obtidos na testemunha $(89,7 \%)$ demonstram a elevada capacidade que tem $B$. sorokiniana de passar da semente para o coleóptilo de plântulas de cevada, fato já reportado em trigo por Forcelini (1992), Reis \& Forcelini (1993), Toledo et al. (1996), entre outros. Tal capacidade foi favorecida pelas condições proporcionadas, $25 \pm 2{ }^{\circ} \mathrm{C}$ e 80 a $95 \%$ de UR, como afirmam Couture \& Sutton (1978), Dehne \& Oerke (1985) e Luz \& Bergstrom (1986). Quanto à eficiência de controle registrada in vitro, onde as combinações fungicidas + PPG melhoraram significativamente a eficiência dos produtos, essas vantagens não se manifestaram in vivo, à exceção do triadimenol. Os resultados obtidos mostram que, em alguns casos, não é preciso erradicar o fungo da semente para evitar a sua passagem para os órgãos aéreos da planta, como aconteceu com o difenoconazole, o qual, ao que parece, graças a sua condição sistêmica e a sua fungitoxicidade, não necessitou do emprego do PPG para impedir a transmissão de $B$. sorokiniana, ainda com níveis aparentes de infecção relativamente altos (in vitro). Comportamento semelhante manifestaram os demais fungicidas sistêmicos, situação que também foi observada por Forcelini (1992). Em geral, os fungicidas testados (exceto o triadimenol) apresentaram baixas eficiências de transmissão do fungo (controle > 90\%) ainda em condições normais (+ água), contrastando com as incidências elevadas alcançadas in vitro. No caso da iminoctadina, a sua elevada eficiência registrada in vitro foi fortemente corroborada in vivo. $\mathrm{O}$ fungicida iprodiona não evitou completamente a passagem do fungo aos órgãos aéreos (98,6\% de controle), ao que parece devido à condição de fungicida protetor, apesar de a sua atividade sistêmica (basipetal e acropetal) ter sido reportada em plantas de Poa sp. (Danneberger \& Vargas, 1982). No caso particular do flutriafol, a capacidade de erradicação registrada in vitro não foi refletida in vivo, situação que também foi reportada por Forcelini (1992) em lotes de sementes com incidência superior a $40 \%$.

Sobre a necessidade de erradicação dos patógenos das sementes, Menten (1996) relata que a simples constatação da presença de um microorganismo, mesmo que patogênico, em determinada semente não é suficiente para garantir a passagem do patógeno para a plântula proveniente da semente infetada. Entretanto, para esse autor, a associação patógeno-semente indica o potencial de transmissão e o conseqüente estabelecimento da doença por ocasião da semeadura no campo se as demais condições do ambiente forem favoráveis.

Tratando-se de um patógeno que afeta a germinação das sementes, o controle de $B$. sorokiniana através do uso de fungicidas pode resultar em incrementos no percentual de emergência das plântulas no campo (Barros \& Salgado, 1983; Barros et al., 1983; Lasca et al., 1985). Nesse sentido, em função dos resultados obtidos neste ensaio, é possível deduzir que o tratamento de sementes com o emprego de solventes orgânicos permite diminuir significativamente a incidência do fungo nas sementes (in vitro), mas não afeta significativamente a percentagem de emergência das plântulas. Forcelini (1992) observou que a emergência de plântulas de trigo foi influenciada positivamente à medida que a semente apresentava menor incidência do fungo $(<50 \%)$, aspecto que, na maioria dos casos, foi melhorado com o tratamento das sementes através do uso de fungicidas. Outros trabalhos realizados por Barros \& Salgado (1983), Barros et al. (1983) e Lasca et al. (1985) destacam o benefício do tratamento de sementes sobre a emergência de plântulas de trigo. Contudo, Forcelini (1992) manifesta que os incrementos na emergência são, geralmente, significativos nos lotes com menor incidência do fungo, pois sementes já debilitadas pelo patógeno não são recuperadas pelo tratamento. Nesse sentido, considerando a incidência da semente empregada neste experimento $(<50 \%)$, deduz-se que esse foi o motivo da ausência de diferenças entre os tratamentos. A combinação triadimenol + PPG foi o único tratamento estatisticamente inferior aos demais. Reis (1987) relata que o fungicida triadimenol pode retardar a velocidade de emergência, reduzir o crescimento inicial das plântulas e provocar o encurtamento do entrenó subcoronal, efeitos fitotóxicos que, possivelmente, foram acentuados pela mescla, reduzindo, dessa maneira, o número de plântulas emergidas.

Segundo Forcelini (1992), se o objetivo do tratamento de sementes fosse simplesmente elevar a germinação, todas as sementes com incidência inferior a 50\% não necessitariam ser tratadas. $\mathrm{O}$ autor, ao analisar o papel epidemiológico da semente na formação de focos primários de infecção na lavoura, concluiu que se o objetivo do tratamento de semente é só o incremento da emergência, e não a redução do nível de incidência do patógeno, um imenso inóculo inicial na lavoura não seria alvo do tratamento. Por essa razão, Reis et al. (1988) salientam que a melhoria da qualidade fisiológica das sementes poderá ser conseqüência, mas não o objetivo do tratamento de sementes. Contudo, o estabelecimento de padrões para o tratamento de sementes não deveria considerar o efeito do patógeno sobre a emergência, mas, sim, o papel epidemiológico do inóculo presente na semente (Forcelini, 1992). 


\section{J.T. Barba et al.}

Finalmente, do presente trabalho conclui-se que a erradicação in vitro de $B$. sorokiniana da semente de cevada é difícil de ser alcançada e nem sempre necessária, uma vez que a simples presença do fungo na semente (especialmente quando tratada com fungicida) não garante a sua transmissão para os órgãos aéreos de plântulas de cevada.

\section{REFERÊNCIAS BIBLIOGRÁFICAS}

BAKER, K.F. \& SMITH, S.H. Dynamics of seed transmission of plant pathogens. Annual Review of Phytopathology 3:311-334. 1966.

BARROS, B.C. \& SALGADO, C.L. Efeito do tratamento de sementes de trigo sobre a emergência e rendimento de grãos. Summa Phytopathologica 9:128-139. 1983.

BARROS, B.C., SALGADO, C.L. \& LASCA, C.C. Ação de fungicidas in vitro sobre a germinação e microflora de sementes de trigo. Summa Phytopathologica 9:118-127. 1983.

BRACCINI, A. de L., RUIZ, H.A. BRACCINI, M. do C.L. \& REIS, M.S. Germinação e vigor de sementes de soja sob estresse hídrico induzido por soluções de cloreto de sódio, manitol e polietileno glicol. Revista Brasileira de Sementes 18:10-16. 1996.

COUTURE, L. \& SUTTON, J.C. Relation of weather variables and host factors to incidence of airborne spores of Bipolaris sorokiniana. Canadian Journal of Botany 56:2162-2170. 1978.

DANNEBERGER, T.K. \& VARGAS, J.M. Jr. Systemic activity of iprodione in Poa annua postinfection activity for Drechslera sorokiniana leaf spot management. Plant Disease 66:914-915. 1982.

DEHNE, H.W. \& OERKE, E. C. Investigations on the occurrence of Cochliobolus sativus on barley and wheat. I. Influence of pathogen, host plant and environment on infection and damage. Zeitschrift für Pflanzenkrankheiten und Pflanzenschutz 92:270-280. 1985.

DIEHL, J.A. \& MINELLA, E. Flora fitopatogênica associada a sementes de cevada no Rio Grande do Sul, 1982-83. Fitopatologia Brasileira 10:443-446. 1985.

DHINGRA, O.D. \& MUCHOVEJ, J.J. Dichloromethane, trichloromethane and carbontetrachloride as solvents for bean seed treatment with systemic fungicides. Seed Science and Technology 8:77-83. 1980.

FORCELINI, C.A. Incidência, transmissão e controle de Bipolaris sorokiniana em sementes de trigo (Tese de Mestrado). Piracicaba, SP. ESALQ. 1992.

GOULART, A.C.P. \& PAIVA, F. de A. Transmissão de Pyricularia oryzae através de sementes de trigo (Triticum aestivum). Fitopatologia Brasileira 15:359-362. 1990.

LASCA, C.C., BARROS, B.C. \& CASTRO, J.L. Danos à cultura do trigo ocasionados por Helminthosporium sativum veiculado por sementes. Summa Phytopathologica 12:17. 1985. (Resumo)

LUZ, W.C. da \& BERGSTROM, G.C. Temperature-sensitive development of spot blotch in spring wheat cultivars differing in resistance. Fitopatologia Brasileira 11:197-204. 1986.

MENTEN, J.O.M. Tratamento de sementes. In Soave, J., Oliveira, M.R.M. \& Menten, J.O.M. (Ed.). Tratamento químico de sementes. Anais, $4^{\text {to }}$ Simpósio Brasileiro de Patologia de Sementes. Gramado, RS. 1996. pp.3-23.

PURCHIO, A.F. \& MUCHOVEJ, J.J. Organic solvents as vehicles of fungicides in seeds of wheat. Fitopatologia Brasileira 15:226228. 1990.

REIS, E.M. Patologia de sementes de cereais de inverno. São Paulo, SP. CNDA. 1987.

REIS, E.M. Selective medium for isolating Cochliobolus sativus from soil. Plant Disease 67:68-70. 1983.

REIS, E.M. \& FORCELINI, C.A. Transmissão de Bipolaris sorokiniana de sementes para órgãos radiculares e aéreos do trigo. Fitopatologia Brasileira 18:76-81. 1993.

REIS, E.M., PICININI, E.C. \& FERNANDES, J.M.C. Estratégias para o controle de doenças do trigo. Embrapa-CNPT. Passo Fundo, RS. 1988.

RICHARDSON, M.J. An annotated list of seed-borne diseases. $3^{\text {rd }}$ ed. CAB. 1979.

TANAKA, M.A.S. \& MACHADO, J.C. Patologia de sementes. Informe Agropecuário 11:40-46. 1985.

TOLEDO, J., ROCA, R.H. \& ESCÓBAR, R.E. Transmisión, persistencia y control químico de Bipolaris sorokiniana causante de la punta negra del grano en trigo. CIAT. Informe Técnico. Proyecto de Investigación Trigo. Santa Cruz de la Sierra, Bolivia. 1996. pp.87106.

VIDHYASEKARAN, P. The use of dichloromethane to incorporate fungicides into rice seeds for control of Drechslera oryzae. Seed Science and Technology 8:357-362. 1980. 